\title{
PSMA-targeted Tubulysin B-containing Conjugate EC1169
}

National Cancer Institute

\section{Source}

National Cancer Institute. PSMA-targeted Tubulysin B-containing Conjugate EC1169. NCI

Thesaurus. Code C117291.

An injectable, water soluble, small molecule drug conjug ate (SMDC) containing a ligand specific for prostate-specific membrane antigen (PSMA), conjug ated via a stable, enzyme-cleavable linker to the cytotoxic agent tubulysin B hydrazide ( $\mathrm{T} \mathrm{ubBH}$ ), with potential antineoplastic activity. Upon administration of PSMA-targeted tubulysin Bcontaining conjug ate EC1169, the PSMA ligand specifically targets and binds to PSMA, a protein which is abundantly expressed on the surface of metastatic and hormonerefractory prostate cancer cells as well as on the neovasculature of many solid tumors. This allows for the specific delivery of T ubBH to PSMA-expressing cancer cells. Upon internalization and cleavage, tubulysin B binds to tubulin and inhibits microtubule polymerization, which blocks cell division and results in G2/M phase arrest, tumor cell apoptosis and a decrease in PSMA-expressing tumor cells. 